\title{
Correlation of numerical and experimental analysis for dynamic behaviour of a body-in- white (BIW) structure
}

\author{
N.A.Z. Abdullah ${ }^{1}$, M.S.M. Sani ${ }^{2,}{ }^{*}, M . M$. Rahman $^{1,2}$ and I. Zaman ${ }^{3}$ \\ ${ }^{1}$ Advance Structural Integrity and Vibration Research (ASIVR), Faculty of Mechanical Engineering, \\ Universiti Malaysia Pahang, 26600 Pekan, Pahang, Malaysia \\ ${ }^{2}$ Automotive Engineering Centre, Universiti Malaysia Pahang, 26600 Pekan, Pahang, Malaysia \\ ${ }^{3}$ Department of Engineering Mechanics, Faculty of Mechanical and Manufacturing Engineering, \\ Universiti Tun Hussein Onn Malaysia, 86400 Parit Raja, Batu Pahat, Johor, Malaysia
}

\begin{abstract}
In order to determine the reliability of data gathered using computational version of finite element analysis, experimental data is often used for validation. In case of finite element analysis, it can sometimes be considered as inaccurate especially when subjected to complex and large structure such as body-in-shite. This is due to difficulties that might occur in modelling of joints, boundary conditions and damping of the structure. In this study, a process of comparison and validation of model based test design with modal testing results was conducted. Modal properties (natural frequencies, mode shapes, and damping ratio) of a body-in-white (BIW) structure were determined using both experimental modal analysis (EMA) and finite element analysis (FEA). Correlation of both sets of data was performed for validation. It appeared that there was significant value of error between those two sets of data. The discrepancies that appear after correlation was then reduced by performing model updating procedure. The results presented here may demonstrate the effectiveness of model updating technique on improving the complex structure such as BIW structure.
\end{abstract}

\section{Introduction}

The trustworthiness of structural mechanical numerical analysis such as finite element analysis (FEA) can always be validated by using experimental analysis data. The difference of values gathered through experiments indicates the level of accuracy for the existing finite element model used in numerical prediction analysis. It is very important to ensure that the existing finite element model that was created during design process is a reliable model and able to provide accurate prediction of structural behavior and performance before the actual structure undergo mass production in manufacturing area. As stated in many previous studies, finite element modeling is the most elementary instruments used to mock up the complex system or structure [1-5]. On the other hand, the body-in-white (BIW) structure,

*Corresponding author: mshahrir@ump.edu.my 
which consists of several sheet metal components welded together, and other numerous types of joints, dents and curvy profile on the structure, can be classified as one complex structure as well. Modeling an exact structure of BIW in finite element can be tricky and very hard to achieve. Thus, the goal of modeling in this case is to come up with a representative model that is simple enough for mathematical manipulation yet capable for describing, inducing, and reasoning complicated phenomena. By using principle from finite element method, a complicated structure, BIW for instance, can be divided into many small elements. The mass and stiffness matrices of each element can be assigned easily. Then the global mass and stiffness matrices of the structure can be assembled using these element matrices by considering connectivity and all the boundary condition [6].

In order to validate the existed finite element model whether it is accurate enough to replicate the response that will be produced by actual structure, many researchers had suggested the usage of modal data gathered both through FEA and experimental modal analysis (EMA) [3, 7-9].The modal properties of the structure in subject which include the natural frequencies, damping ratios, and mode shapes will be obtained through both FEA and EMA. These two sets of data will be correlated in order to calculate the level of discrepancies between them.

While discrepancies between prediction analysis and experimental on the real structure is unavailable due to existence of many local effects that are not taken into account by FE modeling when predicting frequencies and modes, model updating is a method widely suggested and frequently applied when it comes to improve the correlation between FE model and the experimental data [10]. Increase of interest in the field of model updating has been developed throughout the years and quite a number of researchers has demonstrate the effectiveness of model updating procedure in reducing the error between prediction and actual structure [5, 11-15]. In addition, not a few numbers of studies has contributed to the development and improvement of model updating technique [16-20].

Yet, very few studies have done the correlation of dynamics properties and perform globalize model updating procedure on a very complex structure such as BIW. It can be seems from literature survey that most study only demonstrate the procedure of localize model updating on various types of joints, which was shown using simple beam and plate. Thus, the present study deals with correlation of experimental modal data with the data gathered through numerical production of a BIW structure which can be considered as a complex structure and demonstrate the procedure of model updating on the correlated data.

\section{Finite element modelling and analysis}

BIW structure, which is the foundation of vehicle's shape, can be considered as a complex structure. Due to this fact, modeling the structure accordingly to the actual structure might be difficult. Therefore, major simplification in modeling the structure was carried out when constructing the finite element model of the BIW. Most of the indentations and curvatures on the surfaces of the BIW structure, as well as the available joints on the structure, were all neglected during modeling process.

Computer aided design (CAD) model was produced first before being imported into a computer aided engineering (CAE) software, MSC.Nastran/Patran, in order to convert the model into a finite element model. the BIW is modeled according and based on five basic modules consisted in BIW structure, which are the floor and underbody, dash panel assembly, front structure, body sides, and roof assembly. The whole BIW model was modeled as surface structure where the thickness for each surface created will be assigned in properties manager in MSC.Nastran/Patran software.

The finite element model of the BIW was created by using 30911 elements of tria3shaped elements while applying hybrid mesher. Equivalence of nodes was then done with 
equivalence tolerance to be $0.005 \mathrm{~m}$, in order to eliminate the coinciding nodes between each surface. The BIW model was assigned to three different shell properties with the same material properties of steel, which details are shown in Table 1. All those different thickness was assigned according to condition of each surface on actual structure. Thicker properties were assigned due to existing of multilayer and stiffening substructure on each surface. Since the complexness of the BIW structure was ignored on modeling process, the assigned thick properties aims to represent the stiffness of the surface.

In general, floor and underbody, body side, and dash panel surface were assigned with thicker properties while roof and front structure surface were assigned with thinner properties.

Table 1. Nominal value of material properties assigned to BIW model.

\begin{tabular}{|c|c|c|}
\hline \multicolumn{2}{|c|}{ Properties } & Nominal Value \\
\hline \multirow{3}{*}{$\begin{array}{c}\text { Material properties } \\
\text { (Steel) }\end{array}$} & Young's modulus & $200 \mathrm{GPa}$ \\
\cline { 2 - 3 } & Poisson ratio & 0.3 \\
\cline { 2 - 3 } & Density & $7860 \mathrm{~kg} / \mathrm{m}^{3}$ \\
\hline \multirow{3}{*}{ Shell properties } & Thickness 1 & $0.012 \mathrm{~m}$ \\
\cline { 2 - 3 } & Thickness 2 & $0.008 \mathrm{~m}$ \\
\cline { 2 - 3 } & Thickness 3 & $0.006 \mathrm{~m}$ \\
\hline
\end{tabular}

Neither boundary condition nor external forces were applied to the model as the model was let to be in free-free boundary condition for calculation of modal properties using SOL 103 in MSC.Nastran/Patran, which is the solution for the normal modes analysis. The solution of the equation of motion for natural frequencies and normal modes requires a special reduced form of the equation of motion. The reduced equation of motion in matrix form is as shown in Eq. (1)

$$
[M]\{u "\}+[K]\{u\}=0
$$

where $[M]$ is the mass matrix, $[K]$ is the stiffness matrix and $u$ is the vector of the variable describing the motion. Equation 1 was solved by assuming a harmonic solution of the form as Eq. (2)

$$
\{u\}=\{\phi\} \sin \omega t
$$

where $\{\phi\}$ is the eigenvector or mode shape and $\omega$ is the circular natural frequency. This harmonic solution is the key to the numerical solution of the problems and indicates that all the degrees of freedom of the vibrating structure move in asynchronous manner. The structural configuration does not change its basic shape during motion and the only thing that changes is its amplitude. If the differentiation of the assumed harmonic solution is performed and substituted into the equation of motion, the simplification of the equation will be represented as Eq. (3).

$$
\left([K]-\omega^{2}[M]\right)\{\phi\}=0
$$

As Eq. (3) was reduces to an eigenvalue problem, it will be represented as Eq. (4)

$$
[K]-\omega_{i}^{2} M\left\{\phi_{-} i\right\}=0
$$

where $\phi$ is the eigenvector (mode shape) corresponding to its eigenvalue and the eigenvalue $\lambda_{\mathrm{i}}$ is related to the natural frequency as Eq. (5)

$$
f_{i}=\omega_{i} / 2 \pi
$$


where $\mathrm{f}_{\mathrm{i}}$ is the $\mathrm{i}$-th natural frequency; and $\omega_{\mathrm{i}}=\sqrt{ } \lambda_{\mathrm{i}}$. The constructed finite element model as viewed in graphic interface of MSC.Nastran/Patran software is as shown in Figure 1. Meanwhile, the computed first 5 mode shapes obtained in FEA is shown in Figure 2.

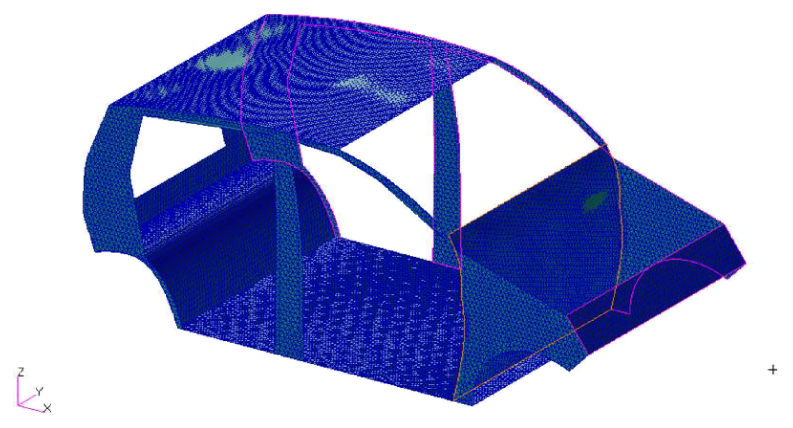

Fig. 1. Finite element model of the BIW structure.

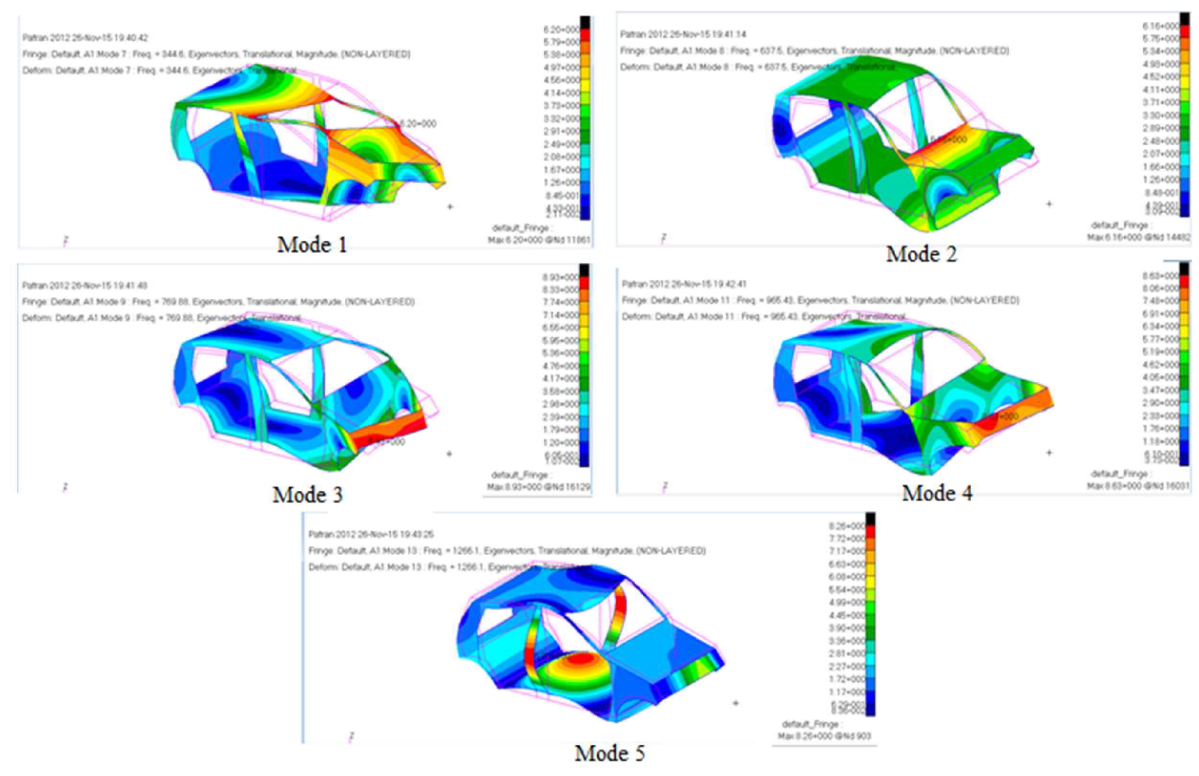

Fig. 2. FEA mode shapes of BIW structure.

\section{Experimental modal analysis}

Experimental modal analysis (EMA) or sometimes called as modal testing, is the process of extracting dynamic characteristics of a system, machinery or structure experimentally. Carrying out EMA on a structure or system has the advantage of having modal characteristic defined from actual measurements. An important property of modes or the measured frequency response functions from a modal testing can be used to describe the structure's dynamic or modal properties, which are the natural frequencies, damping ratios and mode shapes.

There are several types of response domain (whether frequency or time domain) that can be gathered via EMA in order to extract those modal properties. However, the most typical data used for parameter extraction, and was used in this study, are the gathered 
frequency response functions (FRFs), which use excitation input and the corresponding output of the test structure. The method of excitation is the impact hammer test. Impact hammer testing is one of the most frequently used methods in modal. Apart from the ability to compute FRF measurements in an FFR analyzer, impact hammer testing is also a fast, convenient, and low cost way of finding the modes of machines and structure [21].

Before conducting the impact hammer testing, an experimental model of BIW was created by using post-processing software. The model consists of lines and points which virtually represent the geometric shape of the BIW structure (refer Figure 3). Data gathered through numerical analysis was used as guide to perform the experiments in way of indicating the best location for accelerometers on the BIW structure. In order to perform the impact hammer test, the BIW structure was hanged from a test rig by using towing cable in order to put the structure under free-free boundary condition (see Figure 4). The measurements were made using a modal analysis software and several other equipment such as PCB 086D20 impact hammer with medium soft tip attached, 4-channel NI DAQ device, and a tri-axial PCB accelerometer. Roving accelerometer method was adopted for the testing procedure, where one knocking point and 59 measurement points was assigned on the structure. Roving accelerometer test was done by creating initial disturbance on the BIW structure at one fixed position while the single tri-axial accelerometer was roved around other measurement points. Nodal points were ensured to be avoided when choosing the impact and measurement point. The vibrational response was measured by using the 4channel NI DAQ device. Curve fitting procedure available in the modal analysis software was used to extract the modal properties of the BIW structure from the computed FRFs.

The computed FRF based on all measurement points is shown in Figure 5. The estimated modal parameters were extracted by applying curve fitting method to the FRF graph in order to obtain a set of experimental derived data. The outcome of curve fitting, which is a set of modal parameters, which consist of natural frequencies, damping and residues, for each of the identified modes within the range of frequency of interest, is shown in Figure 6. After curve fitting process was completed, the modal parameters are stored in a Shape Table as residue mode shapes. The mode shapes was then displayed through the created experimental model. The computed modal parameters are shown in Figure 6. According to the computed FRF graph, the natural frequency for the first mode is $7.84 \mathrm{~Hz}$.

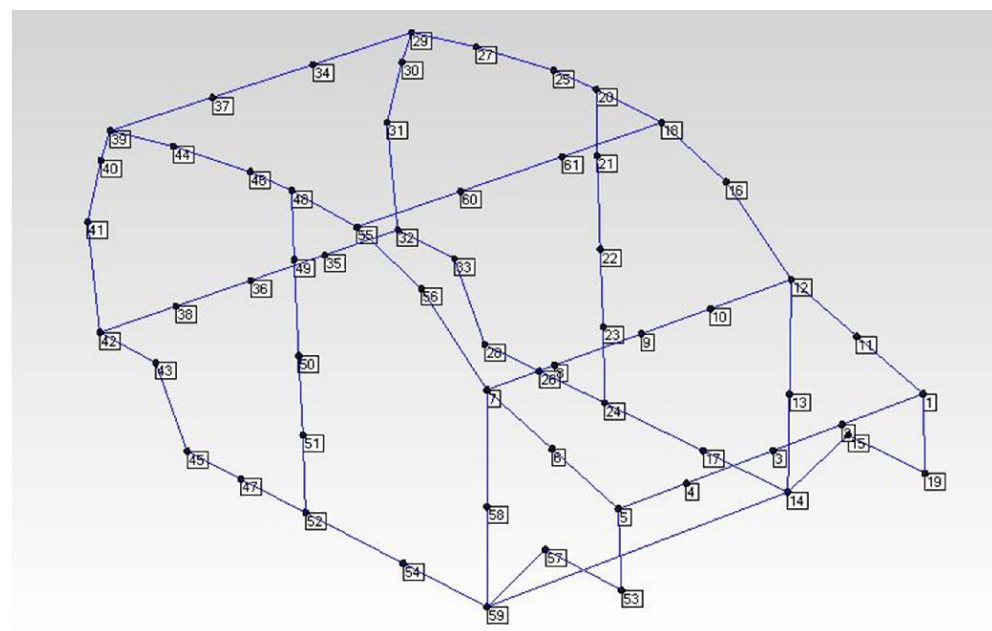

Fig. 3. Experimental model of BIW structure. 


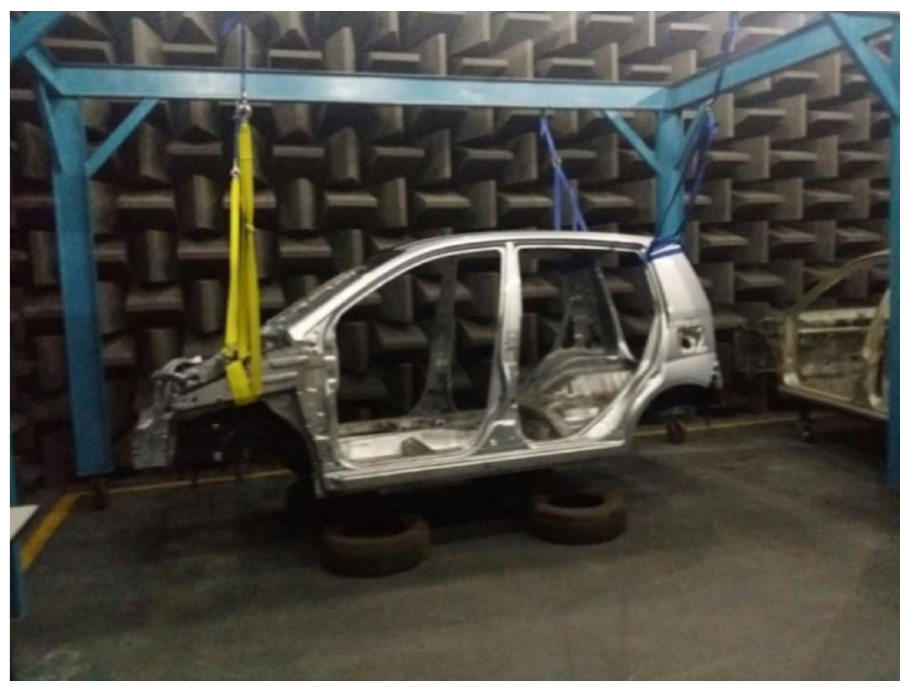

Fig. 4. Hanging BIW structure under free-free boundary condition.
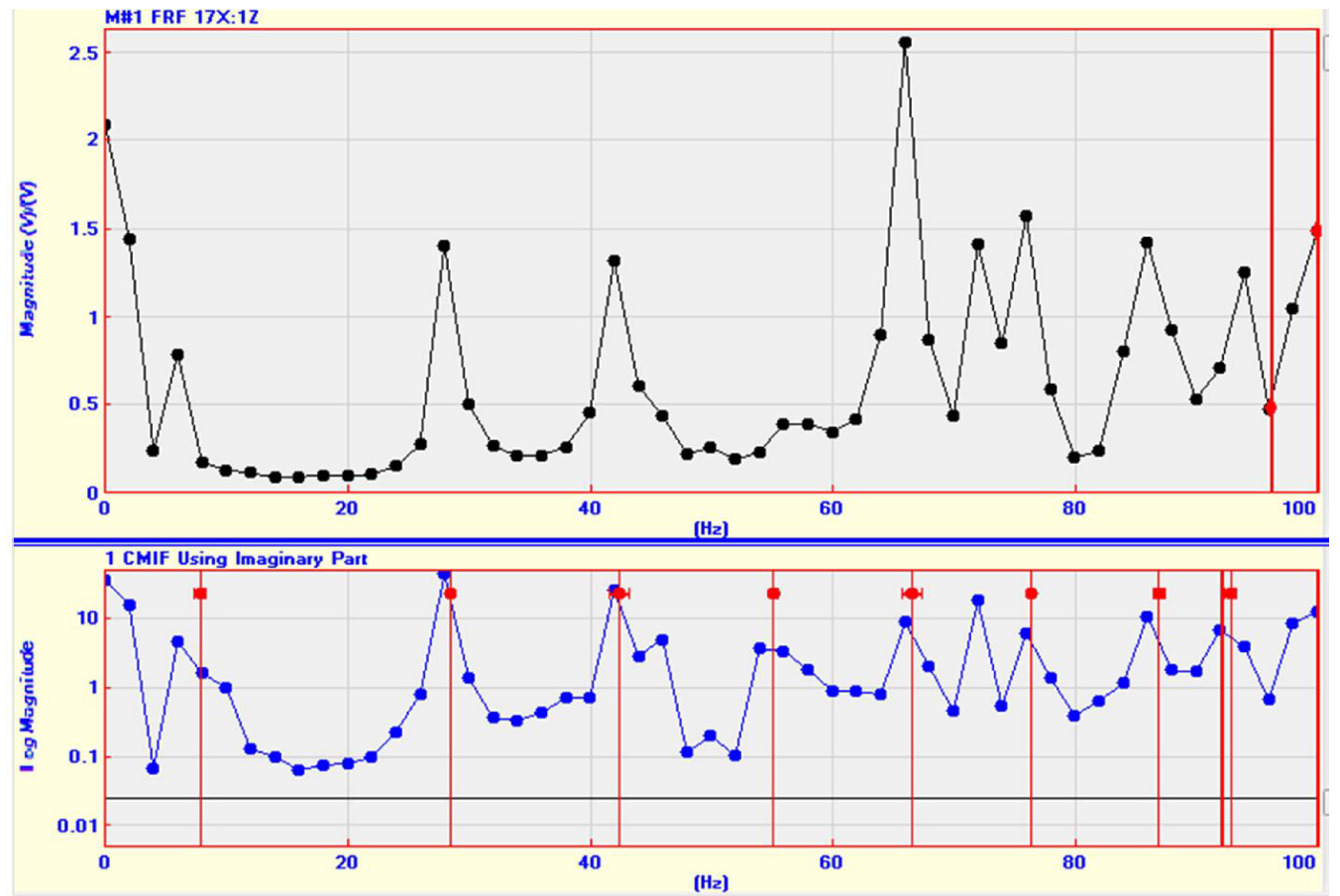

Fig. 5. Computed FRF for all measurement points. 


\begin{tabular}{|c|c|c|c|c|c|c|}
\hline \hline & $\begin{array}{c}\text { Select } \\
\text { Mode }\end{array}$ & $\begin{array}{c}\text { Frequency } \\
(\mathrm{Hz})\end{array}$ & $\begin{array}{c}\text { Damping } \\
(\mathrm{Hz})\end{array}$ & $\begin{array}{c}\text { Damping } \\
(\%)\end{array}$ & $\begin{array}{c}\text { Residue } \\
\text { Mag }\end{array}$ & $\begin{array}{c}\text { Residue } \\
\text { Phs }(\mathrm{deg})\end{array}$ \\
\hline 1 & Yes & 7.84 & 0.453 & 5.77 & 2 & -30.7 \\
\hline 2 & Yes & 28.4 & 0.162 & 0.571 & 8.36 & -36.8 \\
\hline 3 & Yes & 42.4 & 0.816 & 1.93 & 14.6 & -172 \\
\hline 4 & Yes & 55.1 & 0.344 & 0.624 & 3.78 & -170 \\
\hline 5 & Yes & 66.4 & 0.815 & 1.23 & 21.1 & -44.4 \\
\hline 6 & Yes & 76.3 & 0.143 & 0.188 & 5.46 & 172 \\
\hline 7 & Yes & 86.8 & 0.466 & 0.537 & 15.4 & 174 \\
\hline 8 & Yes & 92.8 & 0.47 & 0.506 & 8.06 & 176 \\
\hline
\end{tabular}

Fig. 6. Computed modal data from FRF graph.

\section{Correlation and finite element model updating}

Correlation of data that was obtained through finite element analysis and modal testing was conducted in order to analyze the discrepancies existed between those two sets of data. In addition, correlation of data is essential in order to have accurateness estimation on the existing BIW model. Table 2 exhibits the correlation of natural frequencies of BIW structure that was gathered via experimental and numerical (finite element) analysis. Value of discrepancies between those two sets of data was calculated by accepting the value obtained through experiment as the actual value. As illustrated, the percentage of error that exists is significantly high especially in second, third and fourth mode.

Table 2. Correlation of natural frequencies between EMA and FEA.

\begin{tabular}{|c|c|c|c|}
\hline Mode & $\begin{array}{c}\text { Experimental Natural } \\
\text { Frequency (Hz) }\end{array}$ & $\begin{array}{c}\text { Numerical Natural } \\
\text { Frequency (Hz) }\end{array}$ & $\begin{array}{c}\text { Percentage of } \\
\text { Error (\%) }\end{array}$ \\
\hline 1 & 7.84 & 7.41 & 5.48 \\
\hline 2 & 28.40 & 22.78 & 19.79 \\
\hline 3 & 42.40 & 38.65 & 8.84 \\
\hline 4 & 55.10 & 50.07 & 9.13 \\
\hline 5 & 66.40 & 66.01 & 0.59 \\
\hline 6 & 76.30 & 72.89 & 4.47 \\
\hline & & Total Error & 48.30 \\
\hline
\end{tabular}

In order to reduce the existing discrepancies, model updating procedure was applied on the finite element model of BIW, thus improving the model to have better correlation with the actual structure. Several updating parameters (Young's modulus and all the thicknesses used in finite element analysis) were considered to be included in model updating procedure.

Approximation subject to the simple first-order Taylor series expansion was used in SOL 200 in MSC.Natran in order to change the vector $\lambda$ of eigenvalues based on the vector $\theta$ of structure updating parameters as stated in Eq. (6).

$$
\lambda_{(i+1)}=\lambda_{i}+\left[S_{i}\right](\delta \theta)
$$

where $\left[S_{i}\right]$ is a sensitivity matrix of $i$-th iteration, which signify the rate of change of the structural eigenvalues $\lambda_{i}$ with respect to changes in $\delta \theta$. The expression for the eigenvalue sensitivity $S_{-}$i can be stated as Eq. (7).

$$
S_{i}=\left(\delta \lambda_{j}\right) / \delta \theta=\phi_{i}^{T}\left[\delta K / \delta \theta-\lambda_{i}(\delta M / \delta \theta)\right] \phi_{i}
$$


The objective function for the prediction error is defined as Eq. (8).

$$
g(x)=\sum W\left(\left(\omega_{i}^{e} / \omega_{i}^{a}\right)-1\right)^{2}
$$

where $\omega_{i}{ }^{e}$ and $\omega_{i}{ }^{a}$ are the experimental and finite element natural frequencies respectively and $W$ is the weighting factor for each mode.

The number of updating parameters was kept to be less than number of modes to be updated in order to avoid ill-conditioning problem in updating procedure. The sensitivity analysis was carried out in the first place in the interest of ensuring that the selected updating parameters were meaningful. The prediction of objective function $\mathrm{g}(\mathrm{x})$ in updating procedure was set to obtain the minimized value. Therefore, the procedure was kept going until convergence was accomplished when the values of $\mathrm{g}(\mathrm{x})$ is sufficiently small.

Comparison of error in initial finite element results to the experimental results and the error after model updating was performed on the finite element data was illustrated in Table 3. Data from this table can be compared with the data in Table 2 which clearly shows the notable changes in the natural frequency values. The most striking result to emerge from the data is that total percentage of error obtained after applying model updating procedure reduced significantly when compared to the initial results. Although the error for mode 5 in the updated data is greater than the error from the initial model, other modes show noteworthy reduction of error. Thus, the updating procedure can be considered as successful.

On the other hand, the deviations of the updating parameters assigned initially on the BIW structure to the updated value were visible in Table 4. The process of updating achieved convergence after 13 iterations. The finding highlights that Young's modulus, thickness 2 and thickness 3 shows greater increment. This is owing to the reason that these parameters shows higher sensitivity value during sensitivity analysis compared to thickness 1.

Table 3. Comparison of discrepancies between initial and updated results.

\begin{tabular}{|c|c|c|c|c|c|}
\hline Mode & $\begin{array}{c}\text { EMA } \\
\text { Frequency } \\
\mathbf{( H z )}\end{array}$ & $\begin{array}{c}\text { Initial FEA } \\
\text { Natural } \\
\text { Frequency (Hz) }\end{array}$ & $\begin{array}{c}\text { Initial } \\
\text { Percentage } \\
\text { of Error } \\
\mathbf{( \% )}\end{array}$ & $\begin{array}{c}\text { Updated } \\
\text { Numerical } \\
\text { Natural } \\
\text { Frequency (Hz) }\end{array}$ & $\begin{array}{c}\text { Percentage of } \\
\text { Error after } \\
\text { Model } \\
\text { Updating (\%) }\end{array}$ \\
\hline 1 & 7.84 & 7.41 & 5.48 & 8.25 & 5.23 \\
\hline 2 & 28.40 & 22.78 & 19.79 & 25.25 & 11.09 \\
\hline 3 & 42.40 & 38.65 & 8.84 & 41.94 & 1.08 \\
\hline 4 & 55.10 & 50.07 & 9.13 & 53.79 & 2.38 \\
\hline 5 & 66.40 & 66.01 & 0.59 & 70.16 & 5.66 \\
\hline 6 & 76.30 & 72.89 & 4.47 & 77.76 & 1.91 \\
\hline & & Total Error & 48.30 & Total Error & 27.36 \\
\hline
\end{tabular}

Table 4. Changes of updating parameters from the initial values.

\begin{tabular}{|c|c|c|c|}
\hline \multirow{2}{*}{ Parameter } & I & II & \multirow{2}{*}{$\begin{array}{c}\text { Deviation (\%) } \\
=\mid(\text { II-I)/I } \mid \times \mathbf{1 0 0}\end{array}$} \\
\cline { 2 - 3 } & Initial Value & Updated Value & 13.17 \\
\hline Young's Modulus (GPa) & 200 & 226.34 & 0.83 \\
\hline Thickness 1 (m) & 0.012 & 0.0121 & 5.00 \\
\hline Thickness 2 (m) & 0.008 & 0.0084 & 18.33 \\
\hline Thickness 3 (m) & 0.006 & 0.0049 & \\
\hline
\end{tabular}

\section{Conclusions}

This study was undertaken to correlate the experimental modal data to the data gathered from finite element analysis of a BIW structure. A finite element model of the BIW 
structure was produced and the percentage of errors between those two sets of data was obtained and the study was furthered into performing model updating procedure in order to reduce the existing percentage of errors. The updating procedure is considered as parameter identification and strikes to improve numerical prediction to be as closely as possible to the actual structure.

Four parameters were chose as the updating parameters and correlation was done based on the first six measured natural frequencies. The results of this investigation show that discrepancy is unavoidable when constructing model for a complex structure such as BIW because of inaccuracies in parameters assumption and simplification in process of modeling. However, this inconsistency between the prediction model and the actual structure can be improved by carrying out model updating procedure.

It is recommended that further research be undertaken by including the joint during modeling process. Therefore, procedure of model updating can be carried out at the joint element and joint properties can be chosen as one of the updating parameters. At the end, the updated finite element model structure can possibly exhibit more accurate and reliable numerical prediction model for future research.

This work was supported and funded by FRGS fund provided by the Ministry of Higher Education (MOHE) under RDU 130149.

\section{References}

1. M. Imregun and W. J. Visser, "A review of model updating techniques," Shock Vib. Dig., 1991.

2. M. I. Friswell and J. E. Mottershead, Finite element model updating in structural dynamics, vol. 38. 1995.

3. D. J. Ewins, "Model validation: Correlation for updating," Sadhana, vol. 25. pp. 221234, 2000.

4. A. Bagchi, "Updating the Mathematical Model of a Structure Using Vibration Data," $J$. Vib. Control, vol. 11, no. 12, pp. 1469-1486, Dec. 2005.

5. N. A. Husain, H. H. Khodaparast, A. Snaylam, S. James, G. Dearden, and H. Ouyang, "Finite-element modelling and updating of laser spot weld joints in a top-hat structure for dynamic analysis," Proc. Inst. Mech. Eng. Part C J. Mech. Eng. Sci., vol. 224, no. 4, pp. 851-861, Apr. 2010.

6. O. C. Zienkiewicz and R. L. Taylor., The Finite Element Method Vol. 1. 1994.

7. M. I. Friswell, J. E. Mottershead, and H. Ahmadian, "Finite-element model updating using experimental test data: parametrization and regularization," Philos. Trans. $R$. Soc. London, Ser. A (Mathematical, Phys. Eng. Sci., vol. 359, pp. 169-186, 2001.

8. G. Banwell, S. Mohr, S. Rothberg, and J. Roberts, "Using experimental modal analysis to validate a finite element model of a tennis racket," Procedia Eng., vol. 34, pp. 688693, 2012.

9. E. Reynders, "System Identification Methods for (Operational) Modal Analysis: Review and Comparison," Arch. Comput. Methods Eng., vol. 19, no. 1, pp. 51-124, 2012.

10. N. A. Z. Abdullah, M. S. M. Sani, M. M. Rahman, and I. Zaman, "A review on model updating in structural dynamics," IOP Conf. Ser. Mater. Sci. Eng., vol. 100, no. 1, p. 012015 , Dec. 2015.

11. N. A. Husain, H. H. Khodaparast, A Snaylam, S. James, M. Sharp, G. Dearden, and H. Ouyang, "Modal testing and finite element model updating of laser spot welds," $J$. Phys. Conf. Ser., vol. 181, p. 012024, Aug. 2009.

12. J. E. Mottershead, M. Link, and M. I. Friswell, "The sensitivity method in finite 
element model updating: A tutorial," Mech. Syst. Signal Process., vol. 25, no. 7, pp. 2275-2296, Oct. 2011.

13. Q. Yuan, "Dual approaches to finite element model updating," J. Comput. Appl. Math., vol. 236, no. 7, pp. 1851-1861, 2012.

14. C. Zang, S. C. Ma, and M. I. Friswell, "Structural model updating with an improved updating parameter selection method," Proceedings of the International Conference on Noise and Vibration Engineering ISMA 2012, 2012.

15. S. N. Zahari, M. S. M. Sani, N. A. Husain, M. Ishak, and I. Zaman, "Dynamic Analysis Of Friction Stir Welding Joints In Dissimilar Material Plate Structure,” J. Teknol., vol. 78, no. 6-9, 2016.

16. Q. Yuan, "A constrained matrix least-squares problem in structural dynamics model updating," J. Comput. Appl. Math., vol. 280, pp. 367-376, May 2015.

17. H. Sun and R. Betti, "A Hybrid Optimization Algorithm with Bayesian Inference for Probabilistic Model Updating," Comput. Civ. Infrastruct. Eng., vol. 30, no. 8, pp. 602619, Aug. 2015.

18. J. Zapico-Valle, R. Alonso-Camblor, M. P. González-Martínez, and M. GarcíaDiéguez, "A new method for finite element model updating in structural dynamics," Mech. Syst. Signal Process., vol. 24, pp. 2137-2159, 2010.

19. S. Adhikari and M. I. Friswell, "Distributed parameter model updating using the Karhunen-Loève expansion," Mech. Syst. Signal Process., vol. 24, no. 2, pp. 326-339, Feb. 2010.

20. W. Wang, J. E. Mottershead, A. Ihle, T. Siebert, and H. Reinhard Schubach, "Finite element model updating from full-field vibration measurement using digital image correlation," J. Sound Vib., vol. 330, no. 8, pp. 1599-1620, Apr. 2011.

21. B. J. Schwarz and M. H. Richardson, "Experimental modal analysis," in CSI Reliability Week, Orlando, FL, 1999, pp. 1-12. 